\title{
Pseudomonas aeruginosa infection in burn patients in Sulaimaniyah, Iraq: risk factors and antibiotic resistance rates
}

\author{
Nasih Othman ${ }^{1}$, Muhammed Babakir-Mina ${ }^{1}$, Chia Kamil Noori ${ }^{2}$, Parihan Yahya Rashid ${ }^{2}$ \\ ${ }^{1}$ Biomedical Research Unit, Sulaimani Polytechnic University, Sulaimaniyah, Iraq \\ ${ }^{2}$ Burns and Plastic Surgery Hospital, Sulaimaniyah, Iraq
}

Key words: Antibiotic resistance; P. aeruginosa; burns; nosocomial infection; Iraqi Kurdistan.

J Infect Dev Ctries 2014; 8(11):1498-1502. doi:10.3855/jidc.4707

(Received 26 January 2014 - Accepted 30 April 2014)

Copyright $(\odot 2014$ Othman et al. This is an open-access article distributed under the Creative Commons Attribution License, which permits unrestricted use, distribution, and reproduction in any medium, provided the original work is properly cited.

Dear Editor,

Colonization of pathogens in burn wounds and their systemic invasion may cause severe complications and death. The two most common pathogens responsible for burn wound infections are Staphylococcus aureus and Pseudomonas aeruginosa [1-5]. Burn wards have been reported to harbor multidrug resistant strains of $P$. aeruginosa which can colonize burn wounds and lead to infection [6]. This pathogen has been reported as the most common source of burn wound infection in the United States [7]. $P$. aeruginosa is also the most common isolate reported among burn patients in Iraqi Kurdistan [8]. This high prevalence of infection and the fact that the pathogen is resistant to many commonly used antibiotics makes a strong case for monitoring this infection in burn wards. Therefore, the current study investigated the risk factors for infection with this pathogen and the antibiotic resistance rates in order to provide evidence for prevention and treatment.

We reviewed the medical records of 985 patients admitted to the Sulaimani Burns and Plastic Surgery Hospital (the Burn Centre) in Iraqi Kurdistan between January 2009 and November 2012. All collected specimens were inoculated on MacConkey agar and Cetrimide agar and incubated at $37^{\circ} \mathrm{C}$ for 24 hours. Subsequently, colorless colonies (non-lactose fermenter) on both MacConkey and Cetrimide agars were subjected to further identification according to Bergey's manual of determinative bacteriology [9]. Final confirmation was made using the analytical profile index (API 20E system) (BioMerieux SA,
Lyon, France). All isolates were tested against eight antibiotic discs using the Kirby-Bauer method.

Culture and sensitivity tests were undertaken for a total of 985 patients (males 43\%, females 57\%). The age ranged from under one to 85 years of age (median 17, IQR 4, 26). The majority of burns were caused by flames $(63 \%)$ and the mean total body surface area burnt (TBSA) was 25\% (SD 15.7\%). Out of 985 patients, a total of 266 patients $(27 \%)$ yielded at least one positive result for $P$. aeruginosa. Characteristics of these 266 patients were compared with those of the rest of the patients.

Factors which were significant at $\mathrm{p} \leq 0.20$ (age, sex, TBSA, mechanism of injury, season and province of residence) were included in the multiple logistic model. No significant interactions or multicollinearity were observed. The Hosmer-Lemeshow test for goodness of fit for the multivariable model was not significant $\left(\chi^{2}=8.9,8 \mathrm{df}, \mathrm{p}=0.4\right)$. The logistic model explained $23 \%$ of the variability in Pseudomonas infection. Adjusted odds ratios are shown in table 1. Female gender, greater burn size, flame burns, winter season and residence in other provinces were significant factors for infection. Females were more at risk of infection than males by almost two fold (OR $1.86,95 \%$ CI [1.22-2.85]). Compared to patients with TBSA less than $25 \%$, patients with burn size greater than $50 \%$ had over six-fold odds of infection (OR $6.57,95 \%$ CI [3.45-12.47]). Compared to scalds, flame injuries had an almost three-fold odds of infection (OR 2.9, 95\% CI [1.79-4.70]). 
Table 1. Adjusted odds ratios and $95 \%$ confidence intervals (CI] for factors significantly associated with Pseudomonas aeruginosa infection

\begin{tabular}{|c|c|c|c|}
\hline \multirow[t]{2}{*}{ Risk factor } & \multirow[t]{2}{*}{ Odds ratio $(95 \%$ CI) } & \multicolumn{2}{|c|}{ Wald test } \\
\hline & & $\mathbf{z}$ & P Value \\
\hline \multicolumn{4}{|l|}{ Sex } \\
\hline Female & $1.86(1.22-2.85)$ & & \\
\hline \multicolumn{4}{|c|}{ Burn size (\%TBSA burnt) } \\
\hline $25.1-50 \%$ & $4.16(2.67-6.47)$ & 6.3 & $<0.001$ \\
\hline Over $50 \%$ & $6.57(3.45-12.47)$ & 5.8 & $<0.001$ \\
\hline \multicolumn{4}{|l|}{ Cause of burn } \\
\hline Scald & Reference group & & \\
\hline Flame & $2.90(1.79-4.70)$ & 4.4 & $<0.001$ \\
\hline Outside city & $1.49(0.95-2.35)$ & 1.7 & 0.09 \\
\hline Other provinces & $2.77(1.37 .5 .60)$ & 2.8 & 0.005 \\
\hline \multicolumn{4}{|l|}{ Season } \\
\hline Summer & Reference group & & \\
\hline Autumn & $1.58(0.84-2.98)$ & 1.42 & 0.15 \\
\hline Winter & $3.9(2.20-6.86)$ & 4.74 & $<0.001$ \\
\hline Spring & $1.71(1.0-2.96)$ & 2.0 & 0.05 \\
\hline
\end{tabular}

Log likelihood $=-301.1$, LR test $\chi^{2}=181.3,10 \mathrm{df}, \mathrm{P}<0.001$; $*$ includes contact, chemical and electrical burns

Table 2. Antibiotic resistance of $P$. aeruginosa in all specimens and in all individual patients (in order of increasing resistance)

\begin{tabular}{|c|c|c|c|c|}
\hline & \multicolumn{2}{|c|}{ Specimens $(n=878) *$} & \multicolumn{2}{|c|}{ Patients $(n=266) *$} \\
\hline & Resistant & Sensitive & Resistant & Sensitive \\
\hline & Number (\%) & Number (\%) & Number (\%) & Number (\%) \\
\hline Meropenem & $310(36.9)$ & $530(63.1)$ & $80(31.0)$ & $178(69.0))$ \\
\hline Amikacin & $503(57.3)$ & $375(42.7)$ & $128(48.1)$ & $138(51.9)$ \\
\hline Cefepime & $544(62.5)$ & $327(37.5)$ & $146(55.1)$ & $119(44.9)$ \\
\hline Ceftazidime & $644(73.6)$ & $231(26.4)$ & $184(69.2)$ & $82(30.8)$ \\
\hline Tobramycin & $669(76.2)$ & $209(23.8)$ & $181(68.1)$ & $85(31.9)$ \\
\hline Gentamicin & $277(85.3)$ & $39(14.7)$ & $777(88.5)$ & $101(11.5)$ \\
\hline
\end{tabular}

\footnotetext{
* There are some missing values in some categories
} 
Patients coming from other provinces had almost three-fold odds of infection compared to patients from Sulaimaniyah city (OR 2.77, 95\% CI [1.37-5.60]). Winter was the worst season for burn infection with $P$. aeruginosa with infection four times as likely as compared to summer (OR 3.9, 95\% CI [2.2-6.86]).

The study included 878 positive specimens for $P$. aeruginosa from 266 patients. Number of positive samples per patient ranged from 1 to 22 samples with a mean of $3.2(\mathrm{SD}=3.1)$ specimens per patient. The majority of the specimens were taken from the lower limbs $(43 \%)$ followed by the trunk $(23 \%)$ and the upper limbs (17\%).

Antibiotic sensitivity tests were undertaken for cefepime, ciprofloxacin, imipenem, meropenem, ceftazidime, amikacin, gentamicin and tobramycin. Table 2 shows number and percentage of cultures resistant and sensitive to each of these antibiotics by number of patients and specimens. The most effective antibiotic was imipenem with $32 \%$ resistance followed by meropenem (37\%) in all specimens. Gentamicin was the least effective antibiotic with $86 \%$ resistance.

Table 3 shows antibiotic resistance in relation to sex, age and site of infection. Females showed significantly more resistance to some antibiotics including ciprofloxacin, ceftazidime, amikacin and tobramycin. In relation to age, there were only significant differences in percentage of resistance to cefepime and tobramycin. In relation to the site of infection, urine specimens showed the highest resistance to all antibiotics. The site of infection was significantly associated with resistance in case of cefepime, imipenem, meropenem, amikacin and tobramycin.

$P$. aeruginosa accounted for $27 \%$ of isolates from burn patients in the present study. This is similar to the $28 \%$ reported by a previous study from the same city [8]. A higher prevalence has been reported by studies elsewhere, such as 57\% in Iran [10], 55\% in India [11] and $51 \%$ in Palestine [12]. This may be due the type inclusion criteria for the microorganisms accounted for and cultured. Risk factors for infection with $P$. aeruginosa were: female gender, greater burn size, flame burns, winter season and residence in other provinces. Burn size and depth are generally known to increase the risk of colonization and infection. Residence in other provinces was associated with a three-fold increase in odds of infection, probably due to longer delay between injury and hospitalization, increasing the likelihood of colonization as reported by Pirnay et al [13]. Burn size over $50 \%$ was associated with over six-fold increase in odds of

Table 3. Percentage of P aeruginosa specimens resistant to antibiotics according to sex, age and site of infection

\begin{tabular}{|c|c|c|c|c|c|c|c|c|}
\hline & 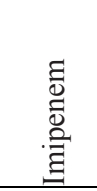 & 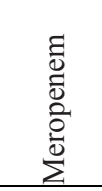 & 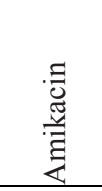 & 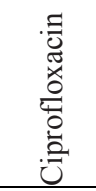 & $\frac{\mathscr{E}}{\stackrel{\Xi}{0}}$ & 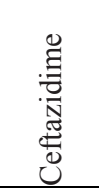 & 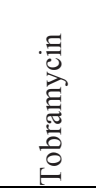 & 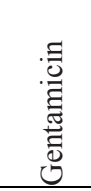 \\
\hline \multicolumn{9}{|l|}{ Sex } \\
\hline Male & $28.5^{*}$ & $31.8^{*}$ & $51.8 \dagger$ & $54.3 \dagger$ & $58.7 *$ & $68.2 \dagger$ & $69.0 \dagger$ & $86.1 *$ \\
\hline $0-5$ & $28.6^{*}$ & $38.6^{*}$ & $52.4^{*}$ & $66.1^{*}$ & $56.9 \dagger$ & $73.7^{*}$ & $68.6 \dagger$ & $84.8^{*}$ \\
\hline $6-14$ & 33.3 & 28.7 & 54.0 & 56.3 & 47.1 & 63.2 & 67.8 & 85.1 \\
\hline $15-59$ & 33.3 & 38.3 & 59.0 & 60.7 & 65.8 & 74.9 & 79.2 & 89.5 \\
\hline Over 59 & 16.7 & 23.5 & 61.1 & 77.8 & 61.1 & 83.3 & 66.7 & 88.9 \\
\hline Trunk & 31.2 & 39.0 & 56.9 & 58.9 & 63.0 & 77.4 & 78.2 & 88.6 \\
\hline Lower limb & 31.3 & 36.9 & 57.6 & 60.7 & 63.3 & 72.1 & 77.1 & 87.8 \\
\hline Blood & 41.7 & 52.6 & 66.1 & 72.8 & 66.1 & 76.3 & 81.4 & 93.2 \\
\hline Urine & 80.0 & 95.0 & 90.0 & 85.0 & 100.0 & 95.0 & 95.0 & 95.0 \\
\hline
\end{tabular}


infection which is consistent with studies from Turkey [14] and India [15]. A greater burn size means a greater area of unprotected body surface and a greater chance of colonization. Flame injuries are usually deeper and cause more destruction to the surrounding structures which may facilitate colonization of microorganisms. Association between burn depth and a higher risks of infection has been reported in the literature [15].

In our study imipenem was the most effective antibiotic with $32 \%$ resistance. Other studies have reported variable rates of imipenem resistance such as $4 \%$ in Pakistan [16], 37\% in Tunisia [17], 43\% in Libya [18] and $76 \%$ in Iran [19]. The second most effective antibiotic was meropenem with $37 \%$ resistance. Other studies have reported resistance to meropenem as 1\% in Pakistan [16], 20\% in Iran [19], and $64 \%$ in Libya [18]. Resistance to all other tested antibiotics was over $50 \%$. Resistance rates were generally higher in older patients except in the case of imipenem and meropenem. This may be due to more exposure of the older generation to broad-spectrum antibiotics during their lifetime and the development of cross-resistance. Bacteria recovered from urine and blood specimens showed the highest rates of resistance probably due to higher virulence; the most virulent bacteria are those that overcome the body defenses and gain access to the blood stream and hence show more resistance to antibiotics.

Antibiotic susceptibility of $P$. aeruginosa has changed due to the emergence of multidrug-resistant strains. Therefore it is of vital importance to regularly monitor nosocomial infections in burn units and undertake culture and sensitivity tests to select the most effective antibiotics for treatment.

\section{Acknowledgements}

We cordially thank the management and staff of the Burn Centre, particularly Choman Faraj, Kamaran Amin, Jabar Abdulwahid, Azad Ali, Nigar Mohammad, Mokhtar Hussein, Xarman Ahmed, and Ashna Jamal for their support during data collection. We also thank Hastyar Hamarashid for his valuable comments about lab methods.

\section{References}

1. Abbasi-Montazeri E, Khosravi AD, Feizabadi MM, Goodarzi H, Khoramrooz SS, Mirzaii M, Mirzaii M, Kalantar E, Darban-Sarokhalil D (2013) The prevalence of methicillin resistant Staphylococcus aureus (MRSA) isolates with highlevel mupirocin resistance from patients and personnel in a burn center. Burns : journal of the International Society for Burn Injuries. $201339: 650-654$.

2. Babakir-Mina M, Othman N, Najmuldeen HH, Noori CK, Fatah CF, Perno CF Ciotti M (2012) Antibiotic susceptibility of vancomyin and nitrofurantoin in Staphylococcus aureus isolated from burnt patients in Sulaimaniyah, Iraqi Kurdistan. The new microbiologica 35: 439-446.

3. Prasanna M, Thomas C (1998) A profile of methicillin resistant Staphylococcus aureus infection in the burn center of the Sultanate of Oman. Burns 24: 631-636.

4. Kalantar E, Taherzadeh S, Ghadimi T, Soheili F, Salimizand H, Hedayatnejad A (2012) Pseudomonas aeruginosa, an emerging pathogen among burn patients in Kurdistan Province, Iran. The Southeast Asian journal of tropical medicine and public health 43: 712-717.

5. Belba MK, Petrela EY, Belba AG (2013) Epidemiology of infections in a Burn Unit, Albania. Burns. 39: 1456-1467

6. Japoni A, Farshad S, Alborzi A (2009) Pseudomonas aeruginosa: Burn Infection, Treatment and Antibacterial Resistance Iraian Red Crescent Medical Journal 11: 244-253.

7. Branski LK, Al-Mousawi A, Rivero H, Jeschke MG, Sanford AP, Herndon DN (2009) Emerging infections in burns. Surgical infections.10: 389-397.

8. Othman N. Epidemiology of burn injuries in Sulaymaniyah provice of Iraq (2010). Nottingham: University of Nottingham, UK (PhD thesis).

9. Bergey DH, Holt JG. Bergey's Manual of Determinative Bacteriology (1994). 9th ed. Baltimore: Lippincott Williams \& Wilkins.

10. Estahbanati HK, Kashani PP, Ghanaatpisheh F (2002) Frequency of Pseudomonas aeruginosa serotypes in burn wound infections and their resistance to antibiotics. Burns : journal of the International Society for Burn Injuries. 28: 340348.

11. Rajput A, Saxena R, Singh KP, Kumar V, Singh S, Gupta A, Singh RK (2010). Prevalence and antibiotic resistance pattern of metallo-beta-lactamase-producing Pseudomonas aeruginosa from burn patients--experience of an Indian tertiary care hospital. Journal of burn care \& research : official publication of the American Burn Association. 31: 264-268.

12. Elmanama AA, Laham NA, Tayh GA (2013) Antimicrobial susceptibility of bacterial isolates from burn units in Gaza. Burns : journal of the International Society for Burn Injuries. 39: 1616-1618

13. Pirnay JP, De Vos D, Cochez C, Bilocq F, Pirson J, Struelens M, Duinslaeger L, Cornelis P, Zizi M, Vanderkelen A (2003) Molecular epidemiology of Pseudomonas aeruginosa colonization in a burn unit: persistence of a multidrugresistant clone and a silver sulfadiazine-resistant clone. Journal of clinical microbiology. 41: 1192-1202

14. Alp E, Coruh A, Gunay GK, Yontar Y, Doganay M (2012) Risk factors for nosocomial infection and mortality in burn patients: 10 years of experience at a university hospital. Journal of burn care \& research : official publication of the American Burn Association. 33: 379-385. 
15. Nagesha CN, Shenoy KJ, Chandrashekar MR (1996) Study of burn sepsis with special reference to Pseudomonas aeruginosa. Journal of the Indian Medical Association. 94: 230-233.

16. Ullah F, Malik SA, Ahmed J (2009) Antimicrobial susceptibility and ESBL prevalence in Pseudomonas aeruginosa isolated from burn patients in the North West of Pakistan. Burns : journal of the International Society for Burn Injuries. 35: 1020-1025.

17. Zoghlami A, Kanzari L, Boukadida J, Messadi AA, Ghanem A (2012) Epidemiological profile and antibiotic resistance of Pseudomonas aeruginosa isolates in burn and traumatology center in Tunisia over a three-year period. La Tunisie medicale. 90: 803-806.

18. Zorgani A, Franka RA, Zaidi MM, Alshweref UM, Elgmati $M$ (2010) Trends in nosocomial bloodstream infections in a burn intensive care unit: an eight-year survey. Annals of burns and fire disasters. 23: 88-94.

19. Ranjbar R, Owlia P, Saderi H, Mansouri S, Jonaidi-Jafari N, Izadi M, Farshad S, Arjomandzadegan M (2011) Characterization of Pseudomonas aeruginosa strains isolated from burned patients hospitalized in a major burn center in Tehran, Iran. Acta medica Iranica. 49: 675-679.

\section{Corresponding author}

Dr Nasih Othman

Biomedical Research Unit

Sulaimani Polytechnic University

Sulaimaniyah, Iraq

Phone: + 964(0)7701451633

Email: nasihothman@yahoo.com

Conflict of interests: No conflict of interests is declared. 